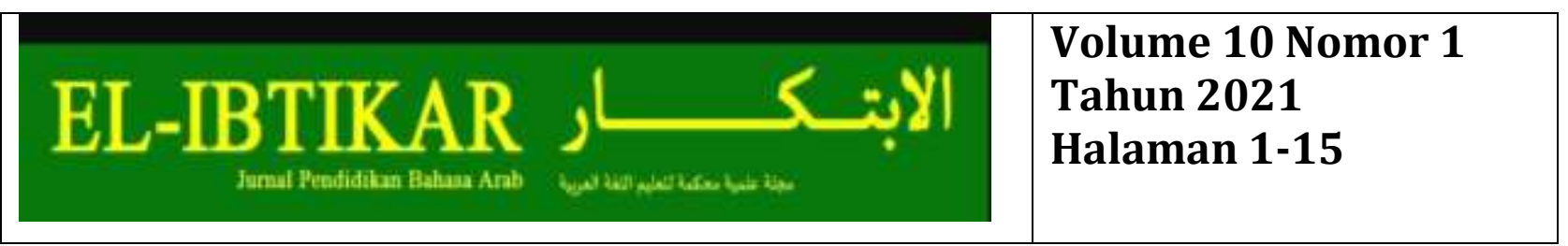

\title{
Tracer Study: Respon Pengguna Lulusan (Stakeholder) terhadap Alumni 2014-2015 pada Jurusan PBA IAIN Syekh Nurjati Cirebon
}

\author{
Nanin Sumiarni \\ Program Studi Pendidikan Bahasa Arab IAIN Syekh Nurjati Cirebon \\ Email: naninsumiarni@syekhnurjati.ac.id \\ Masriah \\ Program Studi Pendidikan Bahasa Arab IAIN Syekh Nurjati Cirebon \\ Email: masriah@syekhnurjati.ac.id
}

Diterima artikel: 05 April 2021

Diterbitkan artikel: 16 Juni 2021

\begin{abstract}
ABSTRAK
Tracer study merupakan salah satu cara bagi perguruan tinggi untuk memperoleh informasi tentang berbagai kekurangan baik dalam proses pembelajaran maupun untuk penyempurna dimasa mendatang. Jurusan Pendidikan Bahasa Arab terutama kurun waktu antara tahun 2014 sampai 2015 setidaknya sudah mencapai 74 orang. Selama kurun waktu tersebut belum pernah dilakukan penelusuran lulusan (tracer study). Jurusan ingin memperoleh informasi atau masukan dari alumni tentang kekurangan yang mungkin terjadi dalam proses pendidikan dan setelah menempuh pendidikan serta respon stakeholder atau pengguna terhadap kompetensi dan kinerja alumni jurusan Pendidikan Bahasa Arab (PBA) IAIN Syekh Nurjati Cirebon. Penelitian ini bertujuan untuk mengetahui : Profil jurusan Pendidikan Bahasa Arab IAIN Syekh Nurjati Cirebon; Profil alumni jurusan Pendidikan Bahasa Arab IAIN Syekh Nurjati Cirebon Tahun 2014/2015; Respon stakeholder terhadap kompetensi dan kinerja alumni jurusan Pendidikan Bahasa Arab IAIN Syekh Nurjati Cirebon Tahun 2014/2015; dan Perbandingan profil lulusan tahun 2012/2013 dengan lulusan 2014 /2015 mengenai kinerja lulusan di lapangan dan respon stakeholder. Penelitian ini termasuk jenis penelitian kuantitatif dengan pendekatan survai, teknik pengumpulan data dengan menggunakan kuesioner. Hasil penelitian menunjukkan bahwa profil alumni PBA adalah menjadi pendidik bahasa Arab di tingkat dasar sampai menengah, menjadi konsultan pengembang pembelajaran bahasa Arab berbasis multimedia, menjadi peneliti pendidikan bahasa Arab tingkat pemula dan penerjemah pemula; sebagian besar alumni tahun 2014/2015 sudah bekerja sebelum lulus sebesar 52\%, mereka bekerja sesuai bidang studi sebesar 64\%, ada yang mendapat gaji pertama sebesar 4-5 juta sebesar $3 \%$. Penilaian alumni terhadap mata kuliah, sistem penilaian dan pelayanan sangat baik. Penilaian stakeholder terhadap kinerja alumni 20142015 sangat baik dan mereka merasa puas sebesar 33\%.
\end{abstract}

Kata Kunci: Tracer Study, Profil lulusan, Respon Stakeholde 


\section{Pendahuluan}

IAIN Syekh Nurjati Cirebon sebagai lembaga pendidikan tinggi Islam yang mencintai perubahan, gandrung pada tantangan dan rindu keunggulan. Semua itu dilakukan untuk menyiapkan mahasiswa agar menjadi anggota masyarakat yang memiliki akhlak karimah, memiliki kemandirian dan daya saing tinggi.

Lulusan perguruan tinggi agama, khususnya IAIN Syekh Nurjati di era global ini menghadapi tantangan tersendiri yang berbeda dengan lulusan perguruan tinggi umum lainnya. Alumni IAIN tidak hanya dituntut untuk mampu menunjukkan profesionalisme sesuai dengan bidang yang digeluti, tetapi juga harus mampu menunjukkan sebagai sarjana agama.

Tantangan ini tidak hanya untuk lulusan saja tetapi juga bagi lembaga itu sendiri harus terus meningkatkan mutu perguruan tinggi untuk mempersiapkan para calon lulusan yang berkualitas mampu bersaing dengan lulusan perguruan tinggi lainnya di dunia kerja

Untuk mengertahui seberapa besar perguruan tinggi mampu berkiprah dalam pembangunan sebagai relevansi pendidikan dapat di lakukan dengan upaya penelusuran terhadap lulusan (tracer study). Tracer studi merupakan pendekatan yang memungkinkan institusi perguruan tinggi memperoleh informasi tentang kekurangan yang mungkin terjadi dalam proses pendidikan dan pembelajaran sebagaimana di jelaskan oleh Harold Schomburg (2003::11), tracer study merupakan pendekatan yang memungkinkan isntitusi pendidikan tinggi memperoleh informasi tentang kekurangan yang mungkin terjadi dalam proses pendidikan dan pembelajaran dan dapat dijadikan dasar untuk perencanaan aktivitas dan untuk penyempurnaan di masa mendatang.

Lulusan sebuah perguruan tinggi tidak dapat dipisahkan dari standar mutu pendidikan yang telah diundang undangkan sebagaimana pasal 1 ayat 17 UU RI Nomor 20 Tahun 2003 menjelaskan bahwa "Standar nasional pendidikan adalah kriteria minimal tentang sistem pendidikan di seluruh wilayah hukum Negara kesatuan Republik Indonesia. Mengenai kriteria minimal standar nasional pendidikan ini terdiri atas standar isi, proses, kompetensi lulusan, tenaga kependidikan, sarana dan prasarana, pengelolaan , pembiayaan 
dan penilaian pendidikan yang dapat dilaksanakan oleh suatu badan standarisasi penjaminan mutu.

Terkait dengan standar kompetensi lulusan Jurusan Pendidikan Bahasa Arab sudah menghasilkan lulusan yang memilki kompetensi pedagogik pada mata pelajaran bahasa Arab, dan pada bidang lainnya sesuai dengan kebutuhan pasar. Lulusan jurusan Pendidikan Bahasa Arab terutama kurun waktu antara tahun 2014 sampai 2015 setidaknya sudah mencapai 74 orang. Selama kurun waktu tersebut belum pernah dilakukan penelusuran lulusan (tracer study) yang memungkinkan jurusan memperoleh informasi atau masukan dari alumni tentang kekurangan yang mungkin terjadi dalam proses pendidikan dan setelah menempuh pendidikan serta respon stakeholder atau pengguna terhadap kompetensi dan kinerja alumni jurusan Pendidikan Bahasa Arab (PBA) IAIN Syekh Nurjati Cirebon.

Oleh karena itu peneliti akan melakukan penelusuran alumni di jurusan Pendidika Bahasa Arab IAIN Syekh nurjati Cirebon dengan mengangkat beberapa rumusan pertanyaan sebagai berikut : a) Bagaimana Profil jurusan Pendidikan Bahasa Arab IAIN Syekh Nurjati Cirebon; b) Bagaimana Profil alumni jurusan Pendidikan Bahasa Arab IAIN Syekh Nurjati Cirebon Tahun 2014/2015; c) Bagaimana Respon Stakeholder terhadap kompetensi dan kinerja alumni jurusan Pendidikan Bahasa Arab IAIN Syekh Nurjati Cirebon Tahun 2014/2015; dan d) Bagaimana Perbandingan profil lulusan tahun 2012/2013 dengan lulusan 2014 /2015 mengenai kinerja lulusan di lapangan dan respon stakeholder.

Berdasarkan latar belakang diatas penelitian ini akan memfokuskan pada kajian: Tracer Study: Respon Pengguna Lulusan (Stakeholder) Terhadap Alumni 2014-2015 Pada Jurusan PBA IAIN Syekh Nurjati Cirebon.

\section{Metode Penelitian}

Penelitian ini termasuk jenis penelitian kuantitatif dengan pendekatan survai. Penelitian ini dilakukan pada bulan Agustus sampai bulan November 2019. Subyek penelitian ini adalah alumni jurusan Pendidikan Bahasa Arab tahun 2014 sampai 2015 
yang berjumlah 74 orang, yang bersedia menjadi responden sebayak 33 orang, serta stakeholder yang telah menerima alumni IAIN bekerja di lembaga atau perusahaannya.

\section{Hasil dan Pembahasan}

Studi penelusuran (tracer study) alumni jurusan Pendidikan Bahasa Arab IAIN Syekh Nurjati Cirebon dilakukan untuk mendeskripsikan profil alumni, respon stakeholder terhadap kompetensi dan kinerja alumni, serta perbandingan profil lulusan tahun 2012/2013 dengan lulusan 2014 /2015 mengenai kinerja lulusan di lapangan dan respon stakeholder.

\section{Profil Lulusan Jurusan Pendidikan Bahasa Arab}

Profil Jurusan Pendidikan Bahasa Arab yang terdiri dari empat yaitu:

\begin{tabular}{|c|c|}
\hline Profil & Deskripsi Profil \\
\hline $\begin{array}{l}\text { Pendidik Bahasa } \\
\text { Arab Tingkat } \\
\text { Sekolah dasar dan } \\
\text { menengah }\end{array}$ & $\begin{array}{l}\text { Pendidik bahasa Arab yang berkepribadian, } \\
\text { berpengetahuan luas, kreatif, mengikuti perkembangan } \\
\text { mutakhir bidang pendidikan bahasa Arab dan mampu } \\
\text { menerapkan teori-teori pendidikan dan pembelajaran }\end{array}$ \\
\hline $\begin{array}{l}\text { Konsultan } \\
\text { Pengembang } \\
\text { Pembelajaran } \\
\text { Bahasa Arab } \\
\text { Berbasis } \\
\text { Multimedia }\end{array}$ & $\begin{array}{l}\text { pengembang bahan ajar Bahasa Arab yang kreatif dan } \\
\text { inovatif berbasis Teknologi Informasi dengan sistem daring } \\
\text { (online) mau pun luring (offline) }\end{array}$ \\
\hline $\begin{array}{l}\text { Peneliti } \\
\text { pendidikan } \\
\text { Bahasa Arab } \\
\text { tingkat pemula }\end{array}$ & $\begin{array}{l}\text { Peneliti yang mampu menganalisa permasalahan } \\
\text { pembelajaran bahasa Arab pada jenjang Pendidikan Dasar } \\
\text { dan Menengah dengan pendekatan ilmiah dan mampu } \\
\text { melaporkannya berdasarkan prinsip-prinsip penulisan } \\
\text { ilmiah }\end{array}$ \\
\hline $\begin{array}{l}\text { Penerjemah } \\
\text { pemula }\end{array}$ & $\begin{array}{l}\text { Penerjemah yang memiliki kemampuan dalam } \\
\text { mengalihbahasakan dari teks sederhana bahasa Arab ke } \\
\text { Indonesia dalam bidang pendidikan, kebahasaan, dan } \\
\text { keagamaan secara tepat, akurat, dan kontekstual }\end{array}$ \\
\hline
\end{tabular}

Profil Alumni Jurusan Pendidikan Bahasa Arab IAIN Syekh Nurjati Cirebon Tahun 2014/2015 
Keterserapan alumni tahun 2014/2015 dalam dunia kerja sangat baik, hal ini dapat dilihat pada waktu tunggu bekerja bahwa mayoritas alumni sudah bekerja sebelum lulus dalam perkuliahan sebanyak 52\%, dengan ditunjukkan dalam diagram berikut:

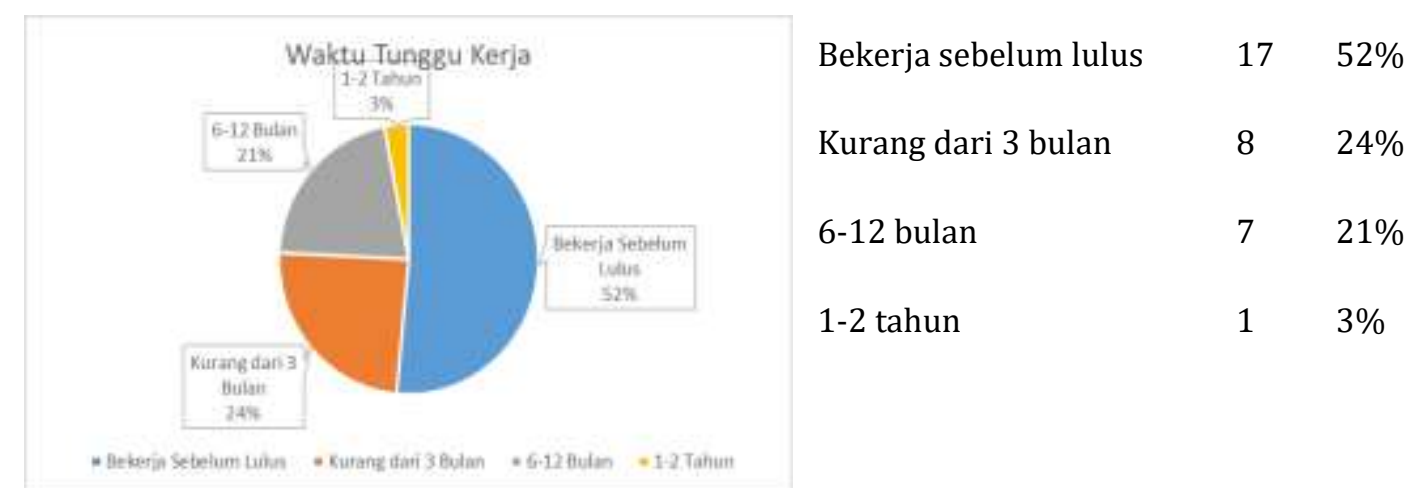

Mayoritas alumni 2014/2015 sudah bekerja sesuai dengan bidang studi sebanyak $64 \%$, hal ini dapat dilihat dari diagram berikut:

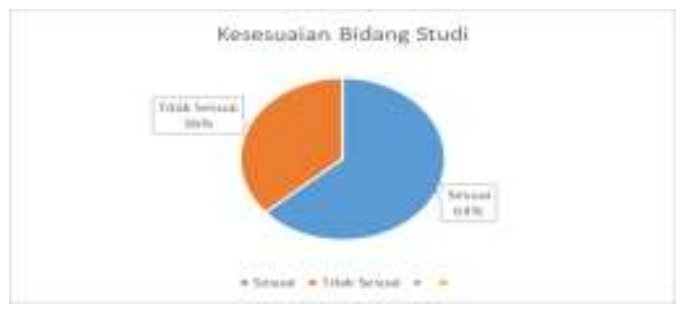

$\begin{array}{lcc}\text { Sesuai } & 21 & 64 \% \\ \text { Tidak sesuai } & 12 & 39 \%\end{array}$

Mayoritas alumni PBA tahun 2014/2015 memperoleh gaji pertama kurang dari 1 juta sebanyak 24 orang (73\%), hal ini dapat dilihat dari diagram berikut:

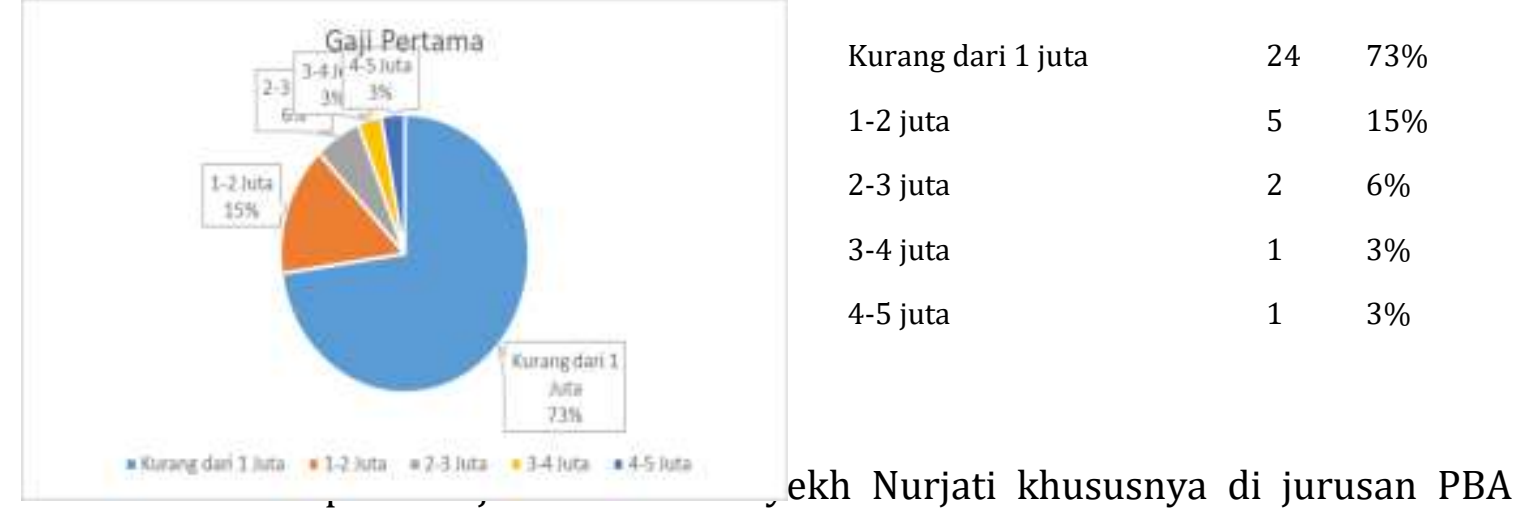

mayoritas alumni menilai baik sebanyak 43\%, bahkan ada yang menilai sangat baik sebanyak 39\%, hal ini dapat dilihat dari grafik berikut: 


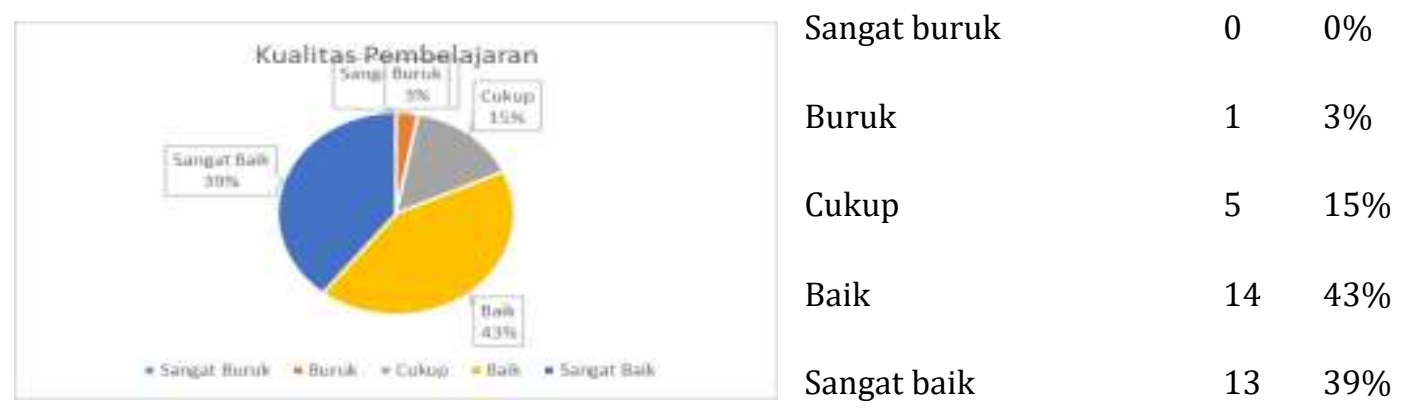

\section{Respon Stakeholder Terhadap Kompetensi Dan Kinerja Alumni Pendidikan Bahasa Arab IAIN Syekh Nurjati Cirebon Tahun 2014/2015}

Data perusahaan/lembaga atau stakeholder yang menjadi responden pada penelitian ini adalah sebagai berikut:

\begin{tabular}{|l|l|l|}
\hline No & \multicolumn{1}{|c|}{ Nama Lembaga } & \multicolumn{1}{|c|}{ Alamat } \\
\hline 1. & IAIN Pekalongan & Jl. Kusumabangsa No 9 Pekalongan \\
\hline 2. & MT Al Ikhlas & $\begin{array}{l}\text { Jl. Pesantren No 05 Dusun Puhun } \\
\text { Rt.09 Rw.03 Desa Jambar Kec. } \\
\text { Nusaherang Kab. Kuningan Jawa } \\
\text { Barat 45563 }\end{array}$ \\
\hline 3. & MA Yapin Kertasmaya & $\begin{array}{l}\text { Jl. By Pass Binaria No 20 Tulungagung } \\
\text { Kertasmaya Indramayu 45274 }\end{array}$ \\
\hline 4. & SMA Nurul Fajri & Waragati Palasah Majalengka \\
\hline 5. & SDIQ Al Bahjah & $\begin{array}{l}\text { Sendang Kecamatan Sumber } \\
\text { Kabupaten Cirebon 45611 }\end{array}$ \\
\hline 6. & SMPIT Nurus & $\begin{array}{l}\text { Jl. Wiratama No 30, Kedungdawa, } \\
\text { Kedawung, Kota Cirebon 45153 }\end{array}$ \\
\hline
\end{tabular}

Dari data yang masuk bahwa stakeholder memperoleh pegawainya melalui informasi lowongan kerja yang penyebarannya melalui iklan di media massa baik televisi, radio, maupun internet sebanyak 30\%, sementara sebanyak $40 \%$ menyatakan pemberitahuan lowongan pekerjaan untuk kalangan terbatas, dan sebanyak 30\% 
stakeholder menerima lamaran langsung dari para lulusan. Hal ini dapat dilihat dari grafik berikut:

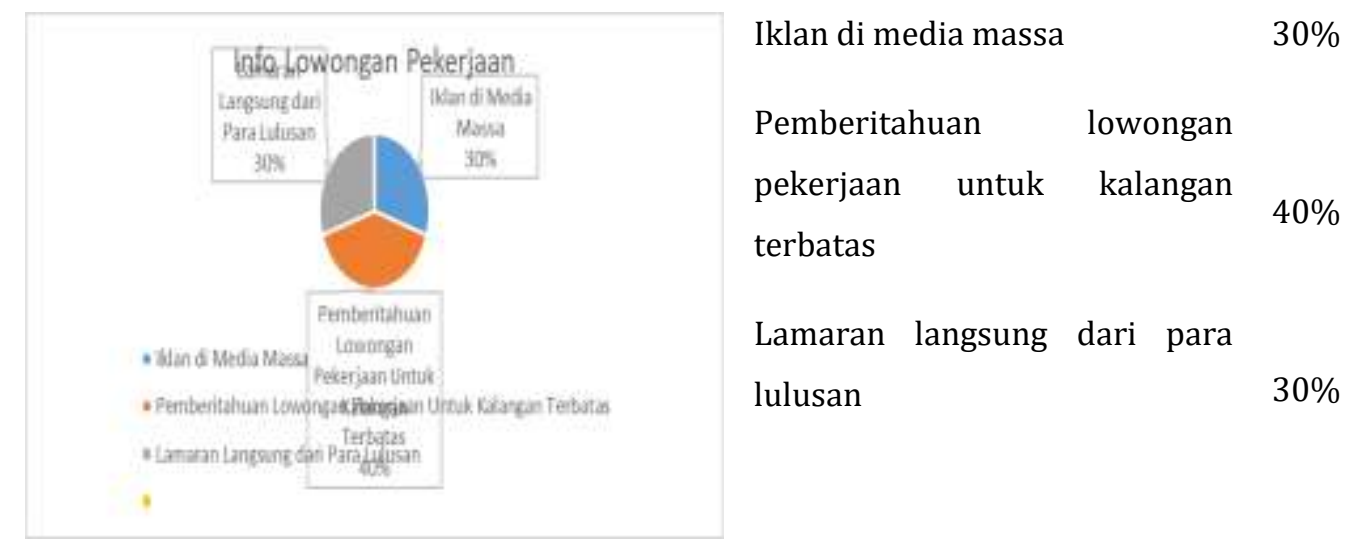

Respon stakeholder terkait kesesuaian alumni dengan bidang pekerjaan yang dilakukan saat ini, sebanyak 4 responden (67\%) menyatakan adanya kesesuaian bidang studi dengan pekerjaan itu sangat penting sekali, sementara 1 responden (17\%) menyatakan penting, dan 1 responden (16\%) menyatakan cukup penting adanya kesesuaian bidang studi dengan pekerjaan. Hal ini dapat dilihat dari grafik berikut:

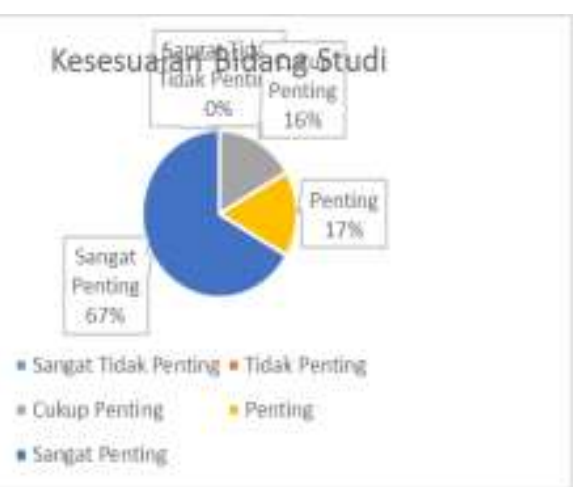

$\begin{array}{ll}\text { Sangat tidak penting } & 0 \% \\ \text { Tidak penting } & 0 \% \\ \text { Cukup penting } & 16 \% \\ \text { Penting } & 17 \% \\ \text { Sangat Penting } & 67 \%\end{array}$

Sebagian stakeholder memberi nilai terhadap pengetahuan bidang ilmu bahasa Arab /pendidikan bahasa Arab yang dimiliki alumni PBA IAIN Syekh Nurjati Cirebon baik (50\%), ada yang memberi nilai sangat baik (33\%) dan cukup baik (17\%). Hal ini dapat dilihat pada grafik berikut:

Pengetahuan Bidang Ilmu Bahasa Arab

/Pendidikana Biathasa Arab

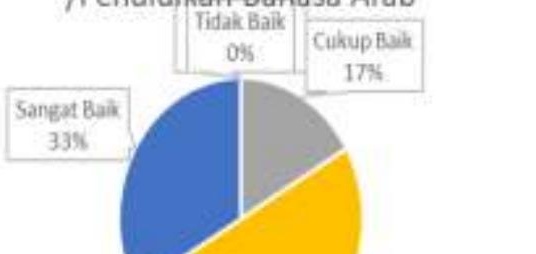




$\begin{array}{lc}\text { Sangat tidak baik } & 0 \% \\ \text { Tidak baik } & 0 \% \\ \text { Cukup baik } & 17 \% \\ \text { Baik } & 50 \% \\ \text { Sangat baik } & 33 \%\end{array}$

Pada aspek kemampuan berkomunikasi dalam bahasa asing secara umum mayoritas stakeholder memberi nilai sangat baik (50\%), baik (17\%), dan cukup baik sebanyak (33\%). Hal ini dapat dilihat dari grafik berikut:

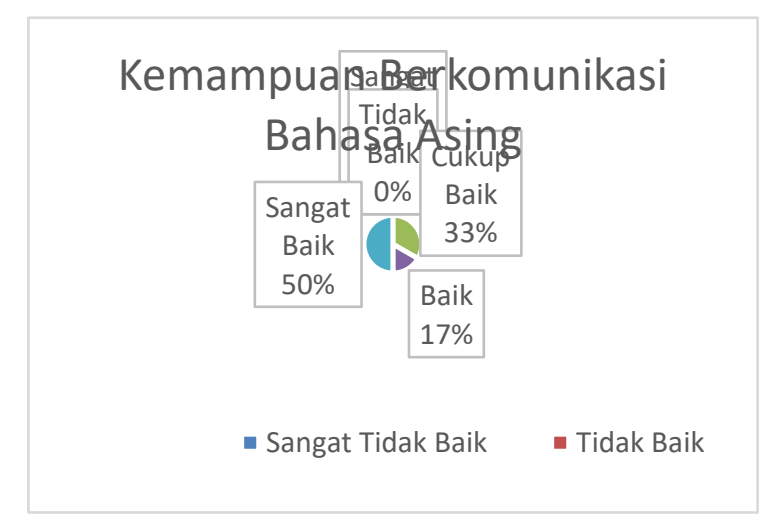

$\begin{array}{ll}\text { Sangat tidak baik } & 0 \% \\ \text { Tidak baik } & 0 \% \\ \text { Cukup baik } & 33 \% \\ \text { Baik } & 33 \% \\ \text { Sangat baik } & 50 \% \\ & \end{array}$

Secara umum mayoritas stakeholder merasa puas terhadap kinerja alumni, karena sebanyak (50\%) alumni bekerja baik, (33\%) stakeholder merasa sangat puas, dan (17\%) cukup puas. Hal ini menunjukkan respon stakholder terhadap kinerja alumni IAIN Syekh Nurjati Cirebon baik dan merasa puas. Dapat dilihat dari grafik berikut:

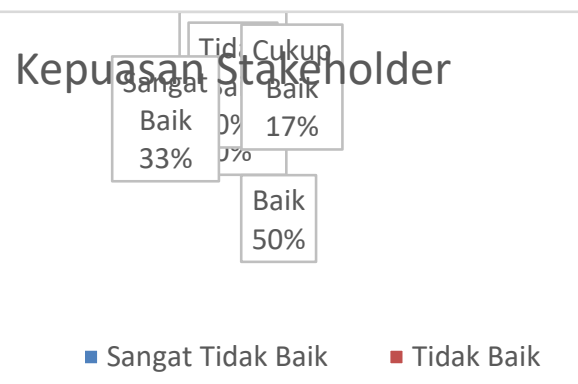

$\begin{array}{ll}\text { Sangat tidak baik } & 0 \% \\ \text { Tidak baik } & 0 \% \\ \text { Cukup baik } & 17 \% \\ \text { Baik } & 50 \% \\ \text { Sangat baik } & 33 \%\end{array}$

\section{Perbandingan Protil Lulusan Tahun 2012/2013}




\section{Dengan Lulusan 2014/2015 Mengenai Kinerja Lulusan Di Lapangan Dan Respon Stakeholder}

Dilihat dari waktu tunggu bekerja alumni tahun 2014/2015 mengalami peningkatan, hal ini dapat dilihat bahwa alumni yang sudah bekerja sebelum lulus mengalami peningkatan dari 34\% untuk alumni tahun 2012/2013 menjadi 52\% untuk alumni tahun 2014/2015. Dapat dilihat dari grafik berikut:

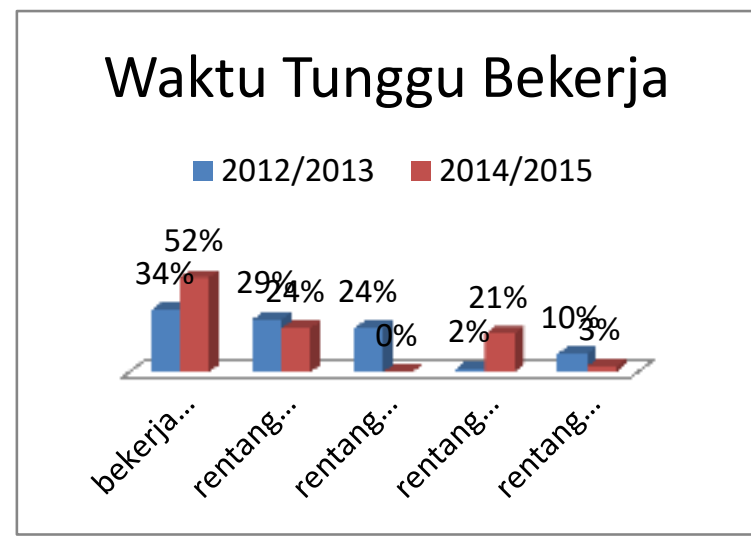

$\begin{array}{lll}\text { Bekerja sebelum lulus } & 34 \% & 52 \% \\ \text { Rentang 0-3 bulan } & 29 \% & 24 \% \\ \text { Rentang 3-6 bulan } & 24 \% & 0 \% \\ \text { Rentang 6-12 tahun } & 2 \% & 21 \% \\ \text { Rentang 1-2 tahun } & 10 \% & 3 \%\end{array}$

Untuk kesesuaian bidang studi dalam bekerja, alumni tahun 2012/2013 sudah bekerja sesuai dengan bidang studi sebanyak 71\% sedangkan alumni 2014/2015 sebanyak 64\%. Hal ini dapat dilihat dari grafik berikut:

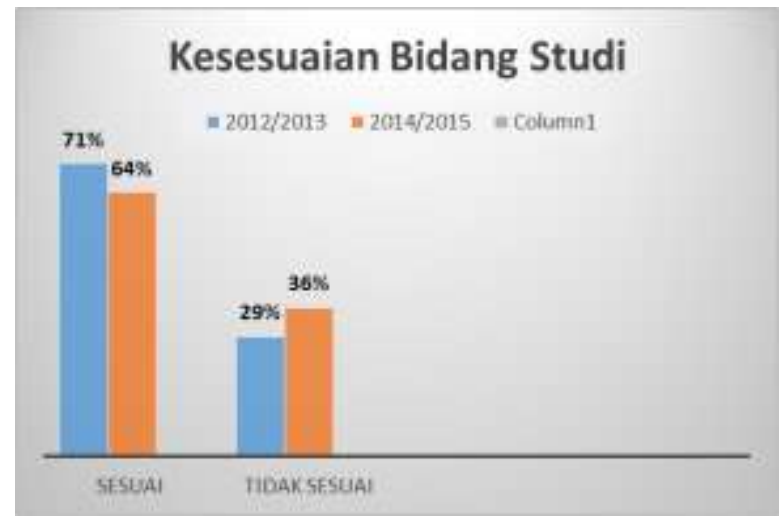

$\begin{array}{lll}\text { Sesuai } & 71 \% & 64 \% \\ \text { Tidak Sesuai } & 29 \% & 36 \%\end{array}$

Gaji pertama yang diperoleh alumni tahun 2014/2015 ada yang mendapatkan gaji pertama sebesar 4-5 juta sebanyak 3\%, dan yang mendapatkan gaji pertama sebesar 3-4 
juta sebanyak 3\% sedangkan alumni tahun 2012/2013 mendapatkan gaji pertama tertinggi sebesar 2-3 juta sebanyak $5 \%$. Hal ini dapat dilihat dari grafik berikut:

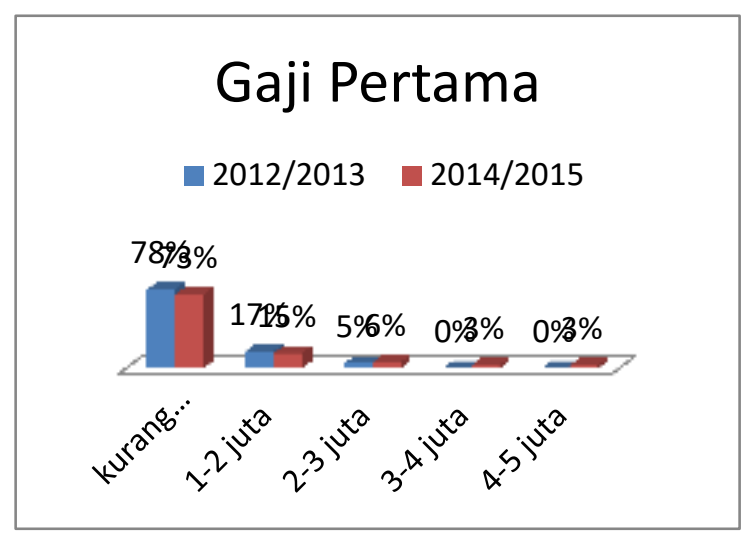

$\begin{array}{lcc}\text { Kurang dari 1 juta } & 78 \% & 73 \% \\ \text { 1-2 juta } & 17 \% & 15 \% \\ \text { 2-3 juta } & 5 \% & 6 \% \\ \text { 3-4 juta } & 0 \% & 3 \% \\ \text { 4-5 juta } & 0 \% & 3 \%\end{array}$

Penilaian alumni tahun 2014/2015 terhadap kualitas pembelajaran lebih baik, terlihat sebanyak 39\% menilai sangat baik, dibandingkan dengan penilaian alumni tahun 2012/2013 sebanyak 15\%, tetapi keduanya sama-sama ada yang menilai buruk sebanyak $3 \%$. Hal ini dapat dilihat dari grafik berikut:

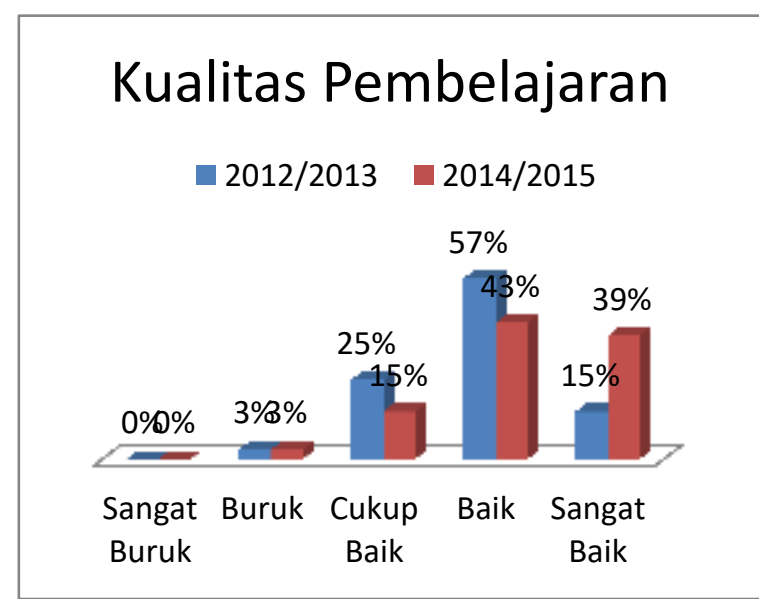

$\begin{array}{lll}\text { Sangat Buruk } & 0 \% & 0 \% \\ \text { Buruk } & 3 \% & 3 \% \\ \text { Cukup Baik } & 25 \% & 15 \% \\ \text { Baik } & 57 \% & 48 \% \\ \text { Sangat baik } & 15 \% & 39 \%\end{array}$

Untuk informasi lowongan pekerjaan yang disampaikan stakeholder pada alumni 2012/2013 mayoritas melalui iklan di media massa sebanyak 55\%, sedangkan pada alumni 2014/2015 mayoritas melalui pemberitahuan lowongan pekerjaan untuk kalangan terbatas sebanyak $40 \%$. Sebagaimana dapat dilihat pada grafik berikut: 


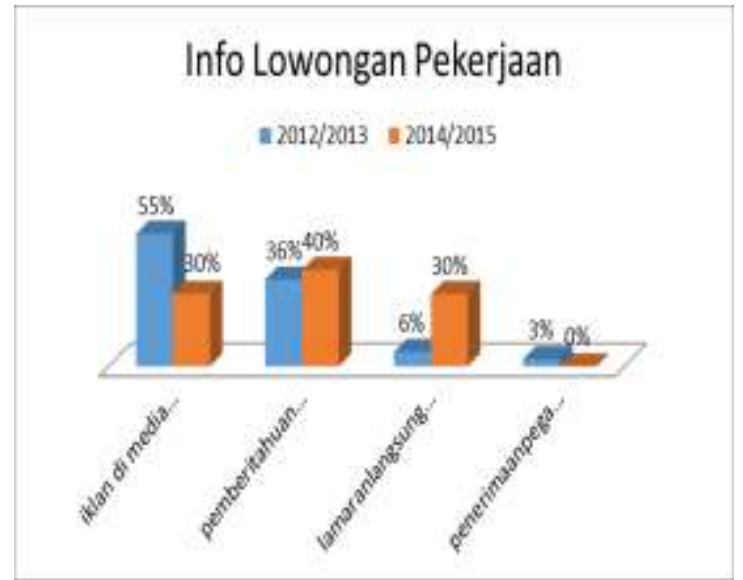

Iklan di media massa

$55 \% \quad 30 \%$

Pemberitahuan lowongan pekerjaan

untuk kalangan terbatas

$36 \% \quad 40 \%$

Lamaran langsung dari para lulusan $\quad 6 \% \quad 30 \%$

$\begin{array}{llll}\text { Penerimaan } & \text { pegawai } & \text { karena } & \\ \text { Hubungan pribadi dengan lulusan } & 3 \% & 0 \%\end{array}$

Untuk kesesuian bidang studi mayoritas stakeholder berpendapat sangat penting baik untuk alumni 2012/2013 (52\%), dan juga untuk alumni 2014/2015 (67\%).

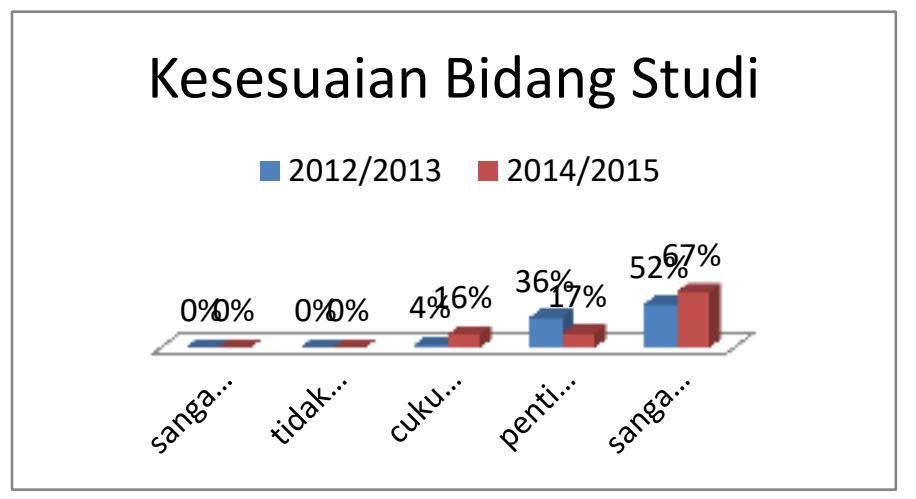

$\begin{array}{lll}\text { Sangat tidak penting } & 0 \% & 0 \% \\ \text { Tidak penting } & 3 \% & 3 \% \\ \text { Cukup penting } & 4 \% & 16 \% \\ \text { Penting } & 36 \% & 17 \% \\ \text { Sangat penting } & 52 \% & 67 \%\end{array}$

Penilaian stakeholder terhadap pengetahuan bidang ilmu bahasa Arab /pendidikan bahasa arab yang dimiliki alumni tahun 2012/2013 mayoritas menilai baik sebanyak 64\%, sedngkan untuk alumni 2014/2015 mayoritas menilai baik sebanyak 50\% bahkan ada yang menilai sangat baik sebanyak 33\%. Hal ini dapat dilihat dari grafik berikut:

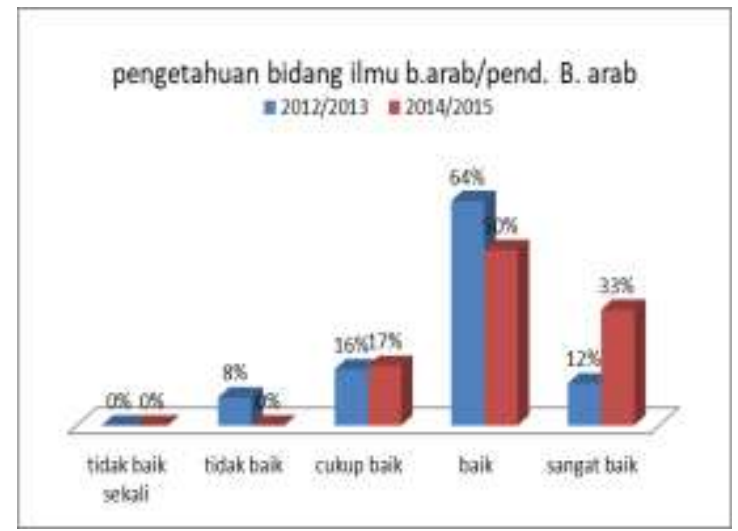

$\begin{array}{lll}\text { Tidak baik sekali } & 0 \% & 0 \% \\ \text { Tidak baik } & 8 \% & 0 \% \\ \text { Cukup baik } & 16 \% & 17 \% \\ \text { Baik } & 64 \% & 50 \% \\ \text { Sangat baik } & 12 \% & 33 \%\end{array}$


Kepuasan stakeholder terhadap kinerja alumni tahun 2012/2013 mayoritas menilai baik sebanyak $72 \%$ dan yang menilai sangat baik sebanya $12 \%$, sedangkan untuk alumni tahun 2014/2015 mayoritas menjawab baik 50\%, bahkan ada yang menilai sangat baik sebanyak 33\%. Hal ini menunjukkan bahwa kepuasan stakeholder terhadap alumni tahun 2014/2015 mengalami peningkatan.

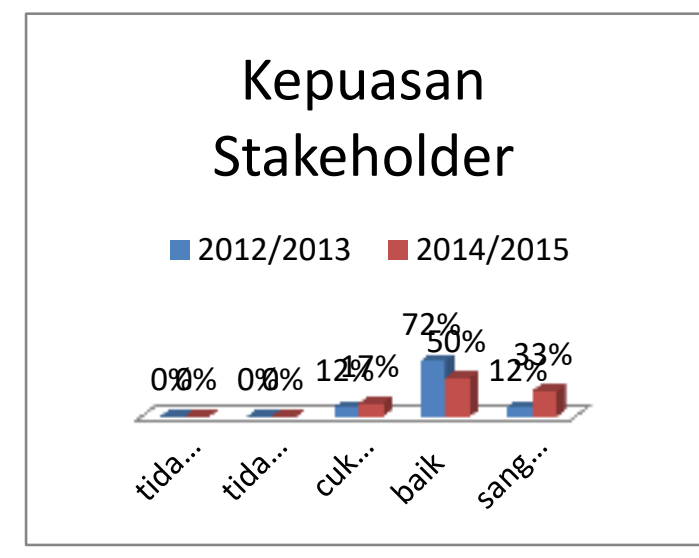

$\begin{array}{lll}\text { Tidak baik sekali } & 0 \% & 0 \% \\ \text { Tidak baik } & 0 \% & 0 \% \\ \text { Cukup baik } & 12 \% & 17 \% \\ \text { Baik } & 72 \% & 50 \% \\ \text { Sangat baik } & 12 \% & 33 \%\end{array}$

\section{Sumbang Saran Alumni dan Stakeholder}

Alumni dan stakeholder memiliki sumbang saran terhadap lembaga yakni: Bersama mewujudkan pendidikan yang meningkatkan keilmuan, moral dan toleransi, Butuh tenaga pengajar laki-laki yang visioner, kreatif, dan aktif, Agar ada hubungan kerjasama kelembagaan dan lulusan, Membuka S2 PBA di IAIN Syekh Nurjati Cirebon, Waktu pelaksanaan PPL untuk mahasiswa diperpanjang minimal 3 bulan, dan lembaga diharapkan dapat lebih meningkatkan lagi kualitas lulusannya.

\section{Kesimpulan}

Berdasarkan hasil penelitian, dapat disimpulkan hal-hal sebagai berikut: Profil lulusan mahasiswa Jurusan Pendidikan Bahasa Arab di IAIN Syekh Nurjati ditetapkan berdasarkan hasil kajian dari kebutuhan pasar kerja yang di butuhkan pemerintah, dunia usaha dan perusahaan untuk mengembangkan ilmu pengetahuan dan teknologi kini memiliki empat profil yaitu: 1) Pendidik bahasa Arab tingkat sekolah dasar dan menengah yang berkompeten baik dalam materi maupun metodologi 2) Pengembang pembelajaran bahasa Arab yang kreatif dan inovatif berbasis multimedia; 3) Menjadi penerjemah Arab Indonesia dalam bidang keagamaan secara tepat, akurat, dan konstektual serta menjadi 
penerjemah tingkat pemula dalam permasalahan pembelajaran bahasa Arab pada jenjang pendidikan dasar dan menengah.

Keterserapan alumni dalam dunia kerja sangat baik hal ini dapat terlihat dalam waktu tunggu bekerja mayoritas alumni 2014/2015 sudah bekerja sebelum lulus. Mayoritas alumni Jurusan Pendidikan Bahasa Arab IAIN Syekh Nurjati bekerja sesuai dengan bidangnya yaitu menjadi guru bahasa Arab baik ditingkat MI MTs maupun MA dan mereka merasakan kemanfaatn belajar dengan kualitas pembelajaran yang sangar baik. Sebagian besar stakeholder atau lembaga yang mempekerjakan alumni jurusan pendidikan bahasa Arab memandang alumni jurusan pendidikan sudah memiliki kompetensi dan pengetahuan tentang kebahasa Araban sudah baik namun perlu ditingkatkan. Karena kemampuan kounikasi bahasa asing bagi guru yang mengajar dilembaganya meupakan sebuah keniscayaan baik kemampuan dalam bahasa Arab maupun bahasa Inggris. Dan untuk pengajar bahasa Arab sudah sesuai bidangnya yang merupakan alumni dari jurusan pendidikan bahasa Arab. Sebagian besar Stakeholder yang ada di wilayah tiga Cirebon sudah merasa puas terhadap kinerja alumni, karena sudah bekerja dengan baik.

Perbandingan profil lulusan PBA Tahun 2012/2013 dengan lulusan 2014/2015 menunjukka bahwa sebagian besar alumni 2014/2015 sudah bekerja sebelum lulus kuliah sebanyak 50\% dibandingkan dengan alumni 2012/2103 sebanyak 34\%; mayoritas alumni tahun 2012/2013 sudah bekerja sesuai dengan bidang studi sebanyak 71\% sedangkan alumni 2014/2015 sebanyak 64\%; untuk gaji pertama yang diterima alumni 2012/2014 dan 2014/2015 mayoritas kurang dari 1 juta, tetapi alumni 2014/2015 ada yang mendapatkan gaji 4-5 juta; mayoritas respon stakeholder terhadap pengetahuan ilmu bahasa Arab/pendidikan bahasa Arab yang dimiliki baik alumni 2012/2013 maupun 2014/2015 baik, tetapi untuk alumni 2014/2015 sebagian stakholder menilai sangat baik sebanyak 33\%; mayoritas stakeholder menilai kinerja alumni, baik alumni 2012/2013 maupun 2014/2015 baik, tetapi untuk alumni 2014/2015 sebagian stakholder menilai sangat baik sebanyak 33\%, Hal ini menunjukkan alumni lulusan tahun 2012/2013 dan 2014/2015 memandang bahwa kepuasan Stakeholder memiliki peranan yang baik dan Stakeholder memiliki kinerja yang baik terhadap pelayanan kepada para alumni. 


\section{Ucapan Terimakasih}

Peneliti dapat menyelesaikan penelitian dengan judul "Tracer Study: Respon Pengguna Lulusan (Stakeholder) Terhadap Alumni 2014-2015 Pada Jurusan PBA IAIN Syekh Nurjati Cirebon". Peneliti mengucapkan terima kasih kepada Kementrian Agama RI atas bantuan dana penelitian DIPA IAIN Syekh Nurjati Cirebon Tahun 2018. Dalam proses penyusunan penelitian ini, penulis telah banyak mendapat arahan, masukan, dan bimbingan yang sangat berharga khususnya dari yang terhormat Prof. Dr. Aziz Fakhrurrazi, MSI, LP2M, kawan kawan peneliti lainnya, dan juga Kementrian Agama RI.

Demikian juga seluruh alumni PBA tahun 2014/2015 dan para stakeholder yang telah bersedia untuk mengisi kuesioner sehingga penelitian ini bisa selesai. Kepada mereka semua peneliti haturkan terima kasih yang sebanyak-banyaknya, jazakumullah khairan katsiran. Semoga penelitian ini dapat menjadi masukan untuk semua pihak terkait.

\section{Referensi}

Ainin ,Moh, 2000, Metodologi Penelitian Bahasa Arab. Surabaya: Hilal Pustaka.

Album wisuda IAIN Syekh Nurjati tahun 2014 dan 2015.

Bakhtiar, Muhammad Ilham, Latif, Suciani. 2017. Jurnal Kajian Bimbingan dan Konseling 2(1), 2017. Tracer Studi Alumni: Upaya Pengembangan Prodi Bimbingan Konseling Universitas Negeri Makasar.

Buku lll A Borang Akreditasi Program Studi Pendidikan Bahasa Arab tahun 2012.

Handayani, Fitri, Asyfiradayati, Rezania. 2017. Prosiding Semnas \& Call For Papers Prodi Kesehatan Masyarakat Fakultas Ilmu Kesehatan, Studi penelusuran (Tracer Study) Alumni Program Studi Kesehatan Masyarakat Fakultas Ilmu Kesehatan Universitas Muhammadiyah Surakarta.

Hasan Alwi KKBI, 2002. Kamus Besar Bahasa Indonesia, Jakarta: Balai Pustaka. Edisi III cetakan ketiga.

John Echol \& Hasan Shadily, 1955. Kamus Inggris-Indonesia. Jakarta: Gramedia Cet.21.

Keputusan Menteri Penddikan Nasional No.045/U/2002 tentang Kurikulum Inti Perguruan Tinggi.

Marwata, 2009. Eksistensi Perguruan Tinggi Swasta, diunduh dari http://cetakkompas.com/read/209/10/14/1101932/eksistensi perguruan tinggi swasta. 
Masri Singaribun \& Sofian Effendi (ed). 1995, Metode Penelitian Survai.Jakarta: LP3ES cetakan 2 .

Millington, Claire, 2006. The Use of Tracer Studies for Enhancing Relevance and Marketability in Online and Distance Education: Barbados Community College.

Mulyadi, 2007, Sistem Perencanaan dan Pengendalian Manajemen, Jakarta: Salembe Amazon.com.

Nazir, M 1988, Metode Penelitian. Jakarta: Ghalia Indonesia

Rasiman, dkk. 2017, Tarbawi: Jurnal Pendidikan Islam Vol. 14, No. 1 (2017): Penelusuran Alumni (Tracer Study) Program Studi Pendidikan Matematika IKIP PGRI Semarang Sebagai Upaya Kajian Relevansi.

Schomburg, Harald 2003. Handbook for graduate tracer study: Moenchebergstrasse Kassel, Germany: Wissenschaftliches Zentrum fur Berufs-und Hochshulforschung, Univessitat Kassel.

Roviaty, Evy, dkk, 2015. Scientiae Educatia Volume 5 Nomor 1 Tahun 2015: Tracer Study: Studi Rekam Jejak Alumni Dan Respons Stakeholder Jurusan Tadris IpaBiologi IAIN Syekh Nurjati Cirebon.

Syafila, Mindriyani, 2005, Tracer Study. Warta Directorat ITB Bandung/

Thahyono, Culture Based Leadership, Jakarta: PT Gramedia Pustaka Utama

Zambere S.N. and Chinyama, diunduh dari http://www. aau.org/studyprogram/notpub 